\title{
NOTES
}

\section{Functional Metallomacrocycles and Their Polymers XXXIII. Autoxidation of Thiol Catalyzed by Thermoelastic Polyurethane Resin Containing a Cobalt(II)phthalocyanine}

\author{
Sadafumi YagI, ${ }^{* 1}$ Mutsumi Kimura, ${ }^{* 2}$ Toshiki Koyama, ${ }^{* 2}$ \\ Kenji Hanabusa, ${ }^{* 2}$ and Hirofusa Shirai ${ }^{* 2}$ \\ ${ }^{* 1}$ Nippon Miractran Co., Ltd., 1667 Onna, Atugi-shi 243, Japan \\ ${ }^{* 2}$ Department of Functional Polymer Science and Technology, Shinshu University, \\ Ueda-shi 386, Japan
}

(Received April 4, 1995)

KEY WORDS Thermoelastic Polyurethane Resin / Cobaltophthalocyanine / Autoxidation / Thiol / Catalytic Activity /

Metallophthalocyanine has attracted considerable interest because of its structural similarity to the active center of naturally occurring haemoenzymes. We studied a series of functional metallophthalocyanines and their polymers as models for catalase, peroxidase, and oxidase. ${ }^{1-5}$

Foul odor is emitted from the spoiled garbage and sewage. Such foul odor results from mercaptan, hydrogen sulfide, and ammonia. Recently, we found that mercaptan and hydrogen sulfide decomposes through the catalytic reaction of $\mathrm{Fe}$ (III)- and $\mathrm{Co}$ (II)phthalocyanine supported on rayon staple fiber. Using this fact, we developed a new type of biomimetic odor-removing fiber. ${ }^{6,7}$

Quite recently, we synthesized thermoelastic polyurethane (TPU) resins containing metallophthalocyanine ring (M-pc, $\mathrm{M}=\mathrm{Fe}$ (III), and $\mathrm{Co}(\mathrm{II})$ ) in the chain. ${ }^{8}$ The introduction of metallophthalocyanine units in a polyurethane had no negative influence upon the principal properties of the practical polyurethane such as melting behavior, dynamic viscoelasticity, tensile properties and thermal properties. These resins may be useful as odor-removing films and fibers.
The autoxidation of thiols was investigated to develop catalysts which could be used for disulfurization of natural odor gas and oil, as well as to clarify the enzymatic removal of thiols.

Numerous attempts have been made in recent years to determine the mechanism of aerobic oxidation of thiols catalyzed by cobaltophthalocyanine polymeric systems. However, no evidence for the reaction catalyzed by polymers containing $\mathrm{Co}(\mathrm{II})-\mathrm{pc}$ in the main chain has been presented. To evaluate the catalytic ability of this $\mathrm{Co}(\mathrm{II})-\mathrm{pc}$ containing polyurethane, we examined the aerobic oxidation of 2-mercaptoethanol catalyzed by $\mathrm{Co}$ (II)-pc containing polyurethane in aqueous solution. Metallophthalocyanine immobilized into the polymer matrix becomes stable and can be repeatedly utilized. Therefore, the stability of the polymer catalyst for the thiol autoxidation reaction was also studied.

\section{EXPERIMENTAL}

\section{Materials}

A thermoelastic polyurethane resin containing a cobalt(II) phthalocyanine ring in the 


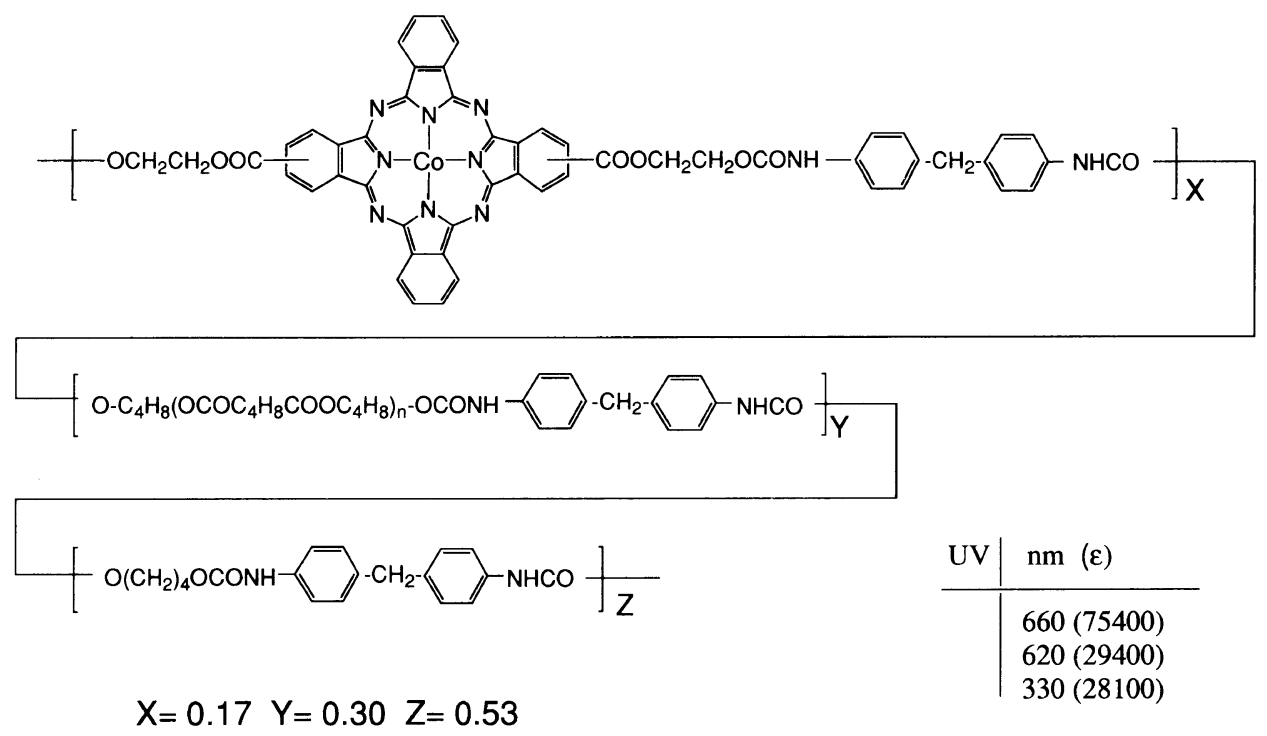

Figure 1. Structure of thermoelastic polyurethane resin containing a cobalt(II) phthalocyanine ring in the chain.

chain (Figure 1) was prepared by the copolyaddition of $4,4^{\prime}$-diphenylmetane diisocyanate (MDI) with a mixture of poly(buthyleneadipate)glycol (PBA), 1,4-butanediol and cobalt(II)-phthalocyanine bis(2-hydroxyethyl carboxylate) (Co(II)-dapc) as described previously. ${ }^{8}$ The copolymer was purified by reprecipitation from $N, N^{\prime}$-dimethylformamide solution with water and ground to a powder (50-70 $\mu \mathrm{m}$ diameter). The copolymer contained $0.5 \mathrm{~mol} \% \mathrm{Co}(\mathrm{II})$-pc ring. 2-Mercaptoethanol (RSH) and other reagents were of analytical grade. Deoxygenated doubly distilled water was used to prepare all solutions. Co(II)-dapc, a low molecular weight compound of $\mathrm{Co}$ (II)-pc-TPU was also prepared and purified as described in a previous paper. ${ }^{9}$

\section{Measurement of Catalytic Activity}

The reaction rates of autoxidation of thiol in the presence of the catalysts were measured based on the oxygen consumption in the reaction mixture with a micro oxygen electrode. All the experiments were conducted at 20 $30^{\circ} \mathrm{C}$ at a shaking speed of $150 \mathrm{rpm}$. Various $\mathrm{pH}$ solutions of $\mathrm{RSH}$ were prepared by mix- ing $0.2 \mathrm{M}-\mathrm{Na}_{2} \mathrm{CO}_{3}$ and $0.2 \mathrm{M}-\mathrm{NaHCO}_{3}$ aqueous solution. The exact concentration of RSH stock solution was determined by reaction with a $\mathrm{I}_{2}$ solution, followed by titrating excess $\mathrm{I}_{2}$ with a $\mathrm{Na}_{2} \mathrm{~S}_{2} \mathrm{O}_{3}$ solution. The initial reaction rate, $V_{0}=-\mathrm{d}\left[\mathrm{O}_{2}\right] / \mathrm{d} t\left(\right.$ in $\left.\mathrm{mol}^{-1} \mathrm{~s}^{-1}\right)$ was taken from the slope of the oxygen consumption. Actually, the amount of RSH oxidized by that of oxygen was calculated from the amount of oxygen consumed.

\section{RESULTS AND DISCUSSION}

Figure 2 shows the amount of oxygen consumed in the autoxidation of RSH catalyzed by $\mathrm{Co}(\mathrm{II})-\mathrm{pc}-\mathrm{TPU}$ in aqueous solution at $\mathrm{pH}$ 10.3 and $30^{\circ} \mathrm{C}$. Oxygen consumption was observed using $\mathrm{Co}$ (II)-pc-TPU as a catalyst. Oxygen consumption was little using the copolyurethane without $\mathrm{Co}(\mathrm{II})$-pc. The autoxidation of thiols obeys eq 1 , in which the consumption of 4 molecules of RSH in accompanied by that of 1 molecule of $\mathrm{O}_{2}$. From Figure 2, the polymer catalyst containing Co(II)-pc catalyzed the autoxidation of RSH in the presence of oxygen. 


$$
4 \mathrm{RSH}+\mathrm{O}_{2} \stackrel{\mathrm{Cat}}{\longrightarrow} 2 \mathrm{RSSR}+2 \mathrm{H}_{2} \mathrm{O}
$$

From the rate of oxygen consumption given Figure 3, catalytic activity (mol thiol/mol $M_{\mathrm{pc}}$ unit $\min ^{-1}$ ) was obtained (Table I). The catalytic activity of dicarboxyphthalocyaninatocobalt(II) (Co(II)-dapc) was also obtained from the rate of oxygen consumption.

The oxidation reaction of $\mathrm{RSH}$ in the presence of $\mathrm{Co}$ (II)-pc-TPU was carried out at various $\mathrm{pH}$. Figure 3 shows the dependence of initial reaction rate $\left(V_{0}\right)$ on $\mathrm{pH}$. $V_{0}$ increased with $\mathrm{pH}$ from 8 to 10 and decreased after passing a maximum at $\mathrm{pH} 10.5$. This is con-

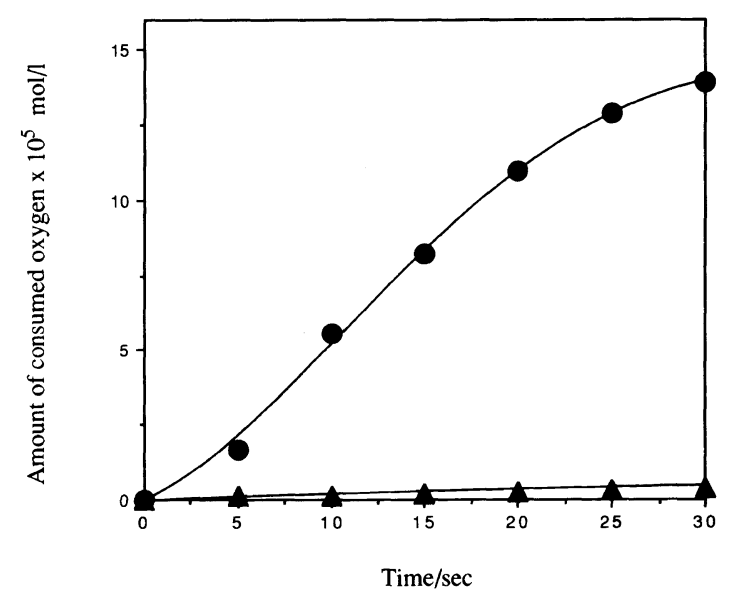

Figure 2. Autoxidation of 2-mercaptoethanol catalyzed by $\mathrm{Co}(\mathrm{II})$-pc-TPU $(\boldsymbol{O})$ and TPU $(\boldsymbol{\Delta})$ in aqueous solution. [Co(II)-pc-TPU], [TPU] $=1 \times 10^{-3} \mathrm{gl}^{-1}(1.1 \times$ $\left.10^{-5} \mathrm{moll}^{-1}\right) ;[\mathrm{RSH}]_{0}=2.5 \times 10^{-2} \mathrm{moll}^{-1} ;\left[\mathrm{O}_{2}\right]_{0}=2.4 \times$ $10^{-4} \mathrm{moll}^{-1} ; \mathrm{pH}=10.3$ at $30^{\circ} \mathrm{C}$. sidered due to the dissociation of $\mathrm{RSH}$, as shown in eq 2, where $\mathrm{RS}^{-}$donates ${ }^{-} \mathrm{SCH}_{2}-$ $\mathrm{CH}_{2} \mathrm{OH}$ species and $K_{\mathrm{RSH}}^{\mathrm{H}}$ is the dissociation constant of thiol group.

$$
\mathrm{RSH} \stackrel{K_{\mathrm{RSH}}^{\mathrm{H}}}{\rightleftarrows} \mathrm{RS}^{-}+\mathrm{H}^{+}
$$

The reactive species for the autoxidation of $\mathrm{RSH}$ is $\mathrm{RS}^{-}$formed by the dissciation of $\mathrm{RSH}$ at high $\mathrm{pH}$ condition $\left(\mathrm{p} K_{\mathrm{a}}=9.60\right)$. The change of $V_{0}$ brought about increased of $\mathrm{RS}^{-}$ concentration at high $\mathrm{pH}$. It is thought that the decrease in $V_{0}$ above $\mathrm{pH} 10.5$ caused competitive inhibition by increasing the concentration of hydroxide ion. Figure 4 shows

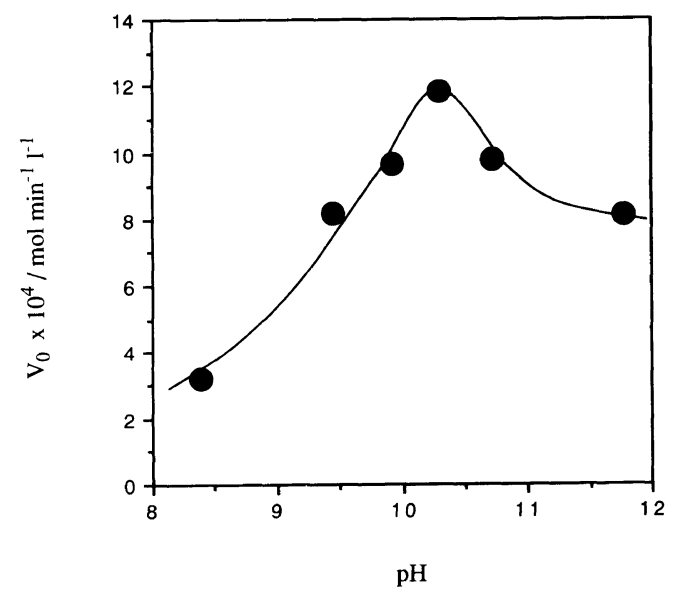

Figure 3. $\mathrm{pH}$ dependence on initial autoxidation rate $\left(V_{0}\right)$ of 2-mercaptoethanol catalyzed by Co(II)-pc-TPU in aqueous solution. $\left[\mathrm{Co}(\mathrm{II})\right.$-pc-TPU] $=1 \times 10^{-3} \mathrm{gl}^{-1}(1.1 \times$ $\left.10^{-5} \mathrm{moll}^{-1}\right) ;[\mathrm{RSH}]_{0}=2 \times 10^{-2} \mathrm{moll}^{-1} ;\left[\mathrm{O}_{2}\right]_{0}=2.4 \times$ $10^{-4} \mathrm{moll}^{-1}$ at $25^{\circ} \mathrm{C}$.

Table I. Kinetic parameters for the autoxidation of 2-mercaptoethanol catalyzed by

\begin{tabular}{|c|c|c|c|c|}
\hline & $\mathrm{O}_{2}$ Consumption & {$[\mathrm{RSH}]$} & [Catalyst] & Turnover \\
\hline & $\mathrm{moll}^{-1} \min ^{-1}$ & $\mathrm{moll}^{-1}$ & $\mathrm{moll}^{-1}$ & number $^{a}$ \\
\hline Co(II)-pc-TPU & $1.12 \times 10^{-3}$ & $3.75 \times 10^{-2}$ & $1.10 \times 10^{-5}$ & 101 \\
\hline Co(II)-dapc & $2.26 \times 10^{-4}$ & $3.75 \times 10^{-3}$ & $9.12 \times 10^{-8}$ & 2480 \\
\hline
\end{tabular}
$\mathrm{Co}(\mathrm{II})$-pc-TPU and $\mathrm{Co}$ (II)-dapc at $30^{\circ} \mathrm{C}$ in aqueous solution at $\mathrm{pH} 10.3$

$$
\text { a Turnover number }=\frac{\mathrm{O}_{2} \text { consumption }}{[\text { catalyst }]}\left(\mathrm{min}^{-1}\right) .
$$




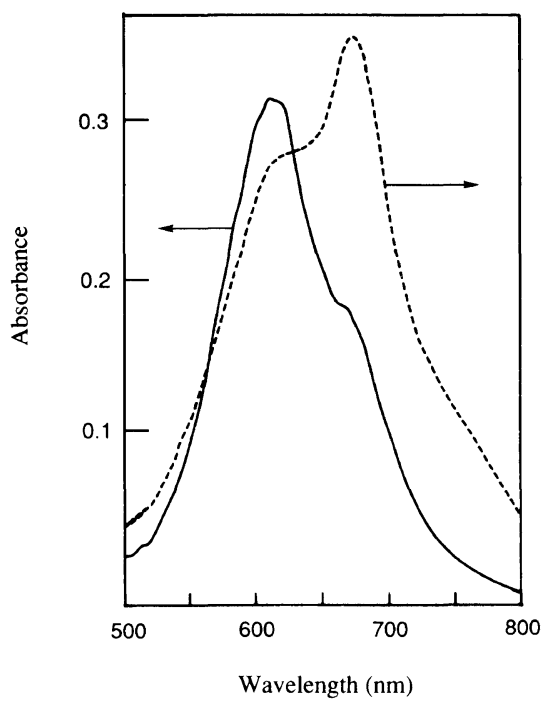

Figure 4. Electronic spectra of $\mathrm{Co}(\mathrm{II})-\mathrm{pc}-\mathrm{TPU}(---)$ in film and $\mathrm{Co}(\mathrm{II})$-dapc $(-)$ in aqueous solution at $\mathrm{pH}$ 10.3.

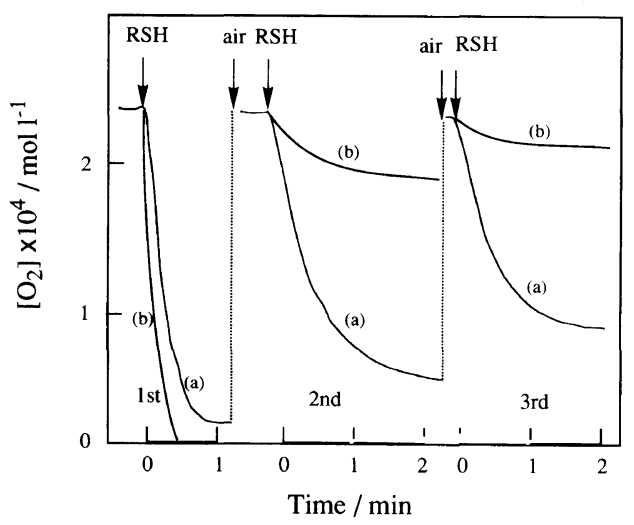

Figure 5. Change in dioxygen concentration with oxidation of 2-mercaptoethanol: $[\mathrm{Co}(\mathrm{II})$-pc-TPU $]=5 \times 10^{-3}$ $\mathrm{gl}^{-1}\left(5.5 \times 10^{-5} \mathrm{moll}^{-1}\right) ;[\mathrm{RSH}]_{0}=6.25 \times 10^{-4} \mathrm{moll}^{-1}$; $\left[\mathrm{O}_{2}\right]_{0}=2.4 \times 10^{-4} \mathrm{moll}^{-1} ; \mathrm{pH}=10.3$ at $30^{\circ} \mathrm{C}$. (a) $\mathrm{Co}(\mathrm{II})-$ pc-TPU; (b) $\mathrm{Co}(\mathrm{II})$-dapc.

the visible spectra of the film of copolyurethane containing $\mathrm{Co}(\mathrm{II})$-pc and aqueous solution of Co(II)-dapc.

The visible spectrum of $\mathrm{Co}(\mathrm{II})$-dapc exhibited absorption with a peak around $620 \mathrm{~nm}$ and a shoulder around $680 \mathrm{~nm}$. The absorption band at $680 \mathrm{~nm}$ is a monomeric species of $\mathrm{Co}$ (II)-pc, and that at $620 \mathrm{~nm}$ is a dimeric species. ${ }^{1}$ From the spectra, it can be seen that the absorption coefficient at $620 \mathrm{~nm}$ of $\mathrm{Co}$ (II)pc bound to the copolyurethane is lower than that of $\mathrm{Co}$ (II)-dapc. This suggests that the aggregation of $\mathrm{Co}(\mathrm{II})$-pc is restricted in copolyurethane by the steric hindrance of the polymer chain. Catalytic activity for autoxidation of RSH by aggregated Co(II)-pc is slightly lower than that of monomeric species. ${ }^{4}$ For the copolyurethane, catalytic activity is nevertheless about one-twenty fifth smaller than that for $\mathrm{Co}$ (II)-dapc. This may be attributed to the fact that the oxidation may mainly proceed on the surface of the polymer. No reaction may occur at the inner part of copolyurethane. The color of $\mathrm{Co}$ (II)-dapc used for the autoxidation of RSH varied from initially green to yellow at the end during the reaction. This means the decomposition of $\mathrm{Co}(\mathrm{II})$-dapc in the process of catalytic reaction. Immobilized natural enzymes on the polymer matrix become stable. Therefore, repeated runs of the autoxidation of thiol catalyzed by $\mathrm{Co}$ (II)-pc-TPU were examined. As shown in Figure 5, the Co(II)pc-TPU is very stable compared with $\mathrm{Co}$ (II)dapc, a low molecular weight catalyst, and can be repeatedly utilized as catalyst for autoxidation of RSH. Co(II)-pc becomes a very stable catalyst for the autoxidation of RSH in the main chain of copolyurethane. Co(II)-pc-TPU can be molded into fibers, film, etc.

Therefore, Co(II)-pc-TPU resins are useful as a new disulfurization material of natural odor gases and oil.

\section{REFERENCES}

1. H. Shirai, A. Maruyama, J. Takano, K. Kobayashi, and N. Hojo, Makromol. Chem., 181, 565 (1980).

2. H. Shirai, S. Higaki, K. Hanabusa, Y. Kondo, and N. Hojo, J. Polym. Sci., Polym. Chem. Ed., 22, 1309 (1984).

3. K. Hanabusa, X. Ye, T. Koyama, A. Kurose, and H. Shirai, J. Mol. Catal., 60, 127 (1990).

4. H. Shirai, H. Tsuiki, E. Masuda, T. Koyama, and K. Hanabusa, J. Phys. Chem., 95, 417 (1991).

5. M. Kimura, T. Dakeno, E. Adachi, T. Koyama, K. Hanabusa, and H. Shirai, Macromol. Chem. Phys., 


\section{Catalytic Activity of Polyurethane with $\mathrm{Co}-\mathrm{Pc}$}

195, 2423 (1994).

6. H. Tsuiki, E. Masuda, T. Koyama, K. Hanabusa, H. Shirai, N. Minamide, Y. Komatsu, and T. Yokozeki, Seni Gakkaishi, in press.

7. H. Shirai, Nippon Kagaku Kaishi (J. Chem. Soc. Jpn., Chem. Ind. Chem.), 1 (1994).
8. S. Yagi, S. Inoue, T. Koyama, K. Hanabusa, and H. Shirai, Koubunshi Ronbunshu, 51, 345 (1994).

9. H. Shirai, K. Hanabusa, M. Kitamura, E. Masuda, O. Hirabara, and N. Hojo, Makromol. Chem., 185, 2537 (1984). 